\title{
BMJ Open A refugee camp in the centre of Europe: clinical characteristics of asylum seekers arriving in Brussels
}

\author{
Gerlant van Berlaer, ${ }^{1,2}$ Francisca Bohle Carbonell, ${ }^{3}$ Sofie Manantsoa, ${ }^{3}$ \\ Xavier de Béthune, ${ }^{3}$ Ronald Buyl, ${ }^{4}$ Michel Debacker, ${ }^{2}$ Ives Hubloue ${ }^{1,2}$
}

To cite: van Berlaer G, Bohle Carbonell F, Manantsoa S, et al. A refugee camp in the centre of Europe: clinical characteristics of asylum seekers arriving in Brussels. BMJ Open 2016;6:e013963. doi:10.1136/bmjopen-2016013963

- Prepublication history and additional material is available. To view please visit the journal (http://dx.doi.org/ 10.1136/bmjopen-2016013963).

Received 20 August 2016 Revised 10 October 2016 Accepted 24 October 2016

\section{CrossMark}

For numbered affiliations see end of article.

\section{Correspondence to}

Dr Gerlant van Berlaer; gerlant.vanberlaer@uzbrussel. be

\section{ABSTRACT}

Background: In the summer of 2015, the exodus of Syrian war refugees and saturation of refugee camps in neighbouring countries led to the influx of asylumseekers in European countries, including Belgium. This study aims to describe the demographic and clinical characteristics of asylum seekers who arrived in a huddled refugee camp, in the centre of a welldeveloped country with all medical facilities.

Methods: Using a descriptive cross-sectional study design, physicians of Médecins du Monde prospectively registered age, gender, origin, medical symptoms and diagnoses of all patients presenting to an erected field hospital in Brussels in September 2015. Diagnoses were post hoc categorised according to the International Classification of Diseases.

Results: Of 4037 patients examined in the field hospital, 3907 were included and analysed for this study. Over $11 \%$ of patients suffered from injuries, but these were outnumbered by the proportion of patients with respiratory (36\%), dental $(9 \%)$, skin $(9 \%)$ and digestive $(8 \%)$ diagnoses. More than $49 \%$ had features of infections at the time of the consultation.

Conclusions: Asylum seekers arriving in a refugee camp in Brussels after a long and hazardous journey suffer mostly from respiratory, dental, skin and digestive diseases. Still, one in seven suffers from injury. These findings, consistent with other reports, should be anticipated when composing emergency medical teams and interagency emergency health or similar kits to be used in a field hospital, even in a Western European country.

Trial registration number: ISRCTN13523620, Results.

\section{INTRODUCTION}

\section{Background/rationale}

Persons fleeing their home country are considered 'asylum seekers' until a contracting state is willing to provide the official status of 'refugee' as disclosed in the Geneva Convention on Refugees. ${ }^{1}$

The continuing exodus from Middle East countries, driven by the Syrian civil war and overcrowding of refugee camps in neighbouring

\section{Strengths and limitations of this study}

- This study includes a considerable number of well documented complaints and physicians' diagnoses in asylum seekers arriving in Western Europe.

- A literature search reveals that epidemiological studies on health problems of asylum seekers in Europe are very scarce, and have not been reported in such detail before.

- The study included only patients self-presenting or referred by outpatient assistance teams to the field hospital in the autumn of 2015, preventing extrapolation to all asylum seekers, and other seasons.

- A number of diagnoses remained tentative, since laboratory and imaging tests were unavailable, and patient anonymity prevented longitudinal follow-up.

- The lack of uniform standards to collect symptoms and diagnoses makes comparison with other data sets challenging.

countries, forced asylum seekers using any conveyance fleeing towards the European Union. In the summer of 2015, the number of asylum seekers in Belgium increased considerably. $^{2}$

People applying for asylum need to register at the Belgian Immigration Office in the centre of Brussels, a necessary step before being entitled to shelter, clothing, food and (medical) assistance. A high daily influx of asylum seekers and a limitation to a maximum of 250 registrations per workday created an accumulation of hundreds, not yet included in the asylum procedure, camping in a park in front of the Belgian Immigration Office. In a spontaneous humanitarian response, volunteers of the ad hoc 'Belgian Civilian Platform' organised an improvised shelter camp and provided clothing and food.

The Belgian branch of the independent international non-governmental organisation Médecins du Monde (MdM) erected a field 
hospital in the camp. MdM provided free medical care, psychological and social support, and sanitary facilities to over 4000 asylum seekers in September 2015.

Of 5512 requests for asylum registered at the Belgian Immigration Office in September 2015, 482 (9\%) were from unaccompanied minors and only 628 were granted asylum. The other applicants were either formally rejected (3526 cases), postponed (748 cases) or definitively refused (610 cases). The latter received an order to leave the territory. ${ }^{2}$ Belgium accepted $0.8 \%$ of all asylum seekers reaching Europe in 2015. ${ }^{3}$

A prerequisite to adopting any evidence-based approach in humanitarian assistance is to assemble solid evidence from results of relevant empirical studies. ${ }^{4}$ Collecting reliable data will always be difficult in emergency situations, as healthcare providers prioritise treating patients over documenting and control groups are usually not available. ${ }^{4-6}$

Reports on refugee camp patients vary widely in methodology, points of interest and are often expert opinions or undocumented statements. Most focus on communicable diseases (vector-borne, airborne, foodborne, blood borne and waterborne diseases and infections) such as tuberculosis, malaria and HIV/AIDS, or elucidate immediate effects of disasters (estimated numbers of dead, injured and displaced) and late consequences such as outbreaks, epidemics and mental health problems. ${ }^{6-10}$ As in every refugee or internally displaced persons camp around the world-usually in third world countriesspecific patterns of pathology are to be expected (especially respiratory, gastrointestinal and skin infections), secondary to poor sanitary conditions and overcrowding, as well as increase of non-communicable diseases (malnutrition, cancer, chronic lung diseases) and comorbidities (especially diabetes and hypertension) imposing vulnerability due to interruption of care, and psychosocial disorders following violence, journeys in austere circumstances, and the settlement in a new, sometimes hostile environment. ${ }^{8}{ }^{11-13}$ A literature search reveals that epidemiological studies on health problems of asylum seekers in Europe are scarce, and that they have been conducted in a wide variety of settings (hospital, asylum home, refugee camp, governmental structures) and have highlighted different issues (hygiene, infectious diseases, chronic health problems, mental health, unaccompanied minors), but never provided a comprehensive and complete overview. ${ }^{8}{ }^{14-17}$ Yet it is estimated that one in six refugees has a physical health problem severe enough to affect their life, and two-thirds have experienced anxiety or depression. ${ }^{18}$

\section{Objectives}

This study aims to document demographics of asylum seekers who arrived in a refugee camp in Brussels in September 2015; to describe symptoms, comorbidities, diagnoses and diagnosis categories of patients presenting to a field hospital in a refugee camp, set up in a
Western European capital; and to formulate recommendations for future relief operations.

\section{MATERIALS AND METHODS}

\section{Study design}

A retrospective descriptive cross-sectional sample analysis was performed on prospectively obtained medical records, collected by MdM from 5 September to 5 October 2015. This time interval corresponds to the period that the refugee camp and field hospital were present in Brussels.

\section{Setting}

Within the refugee camp, MdM erected a level I medical field hospital, consisting of units for 24/7 ambulatory healthcare and psychosocial support. ${ }^{19}$ The MdM volunteer team comprised over 400 certified physicians, nurses, pharmacists, logisticians and interpreters. MdM registered all volunteers and verified their diploma and license to work in Belgium. An outpatient assistance team with a physician, a nurse and an interpreter provided on-the-spot healthcare for patients not able to leave their tents, or referred them to the field hospital for further care when necessary.

Registration on admission and basic triage in urgent and less urgent patients was performed by trained nurses. Each patient was subsequently interviewed and examined by physicians, with competent interpreters present during all clinical encounters. Diagnoses were based on the patients' complaints, symptoms and physical examination, as MdM had limited access to diagnostic capability. Patients were treated on the spot if appropriate, vaccinated when needed and received explanations in their own language. Supplies were retrieved from the MdM stockpile and donations. Patients requiring emergency care, laboratory tests, medical imaging or hospitalisation were transferred to hospitals in the Brussels area. Patients requiring follow-up were requested to re-present to the field hospital or referred to primary or dental care facilities, or newborn consultations, with referral letters.

\section{Participants}

All patients presenting spontaneously to the field hospital or examined by the outpatient assistance teams were eligible for inclusion. Patients with missing date of presentation, chief complaint or single primary diagnosis were excluded afterwards. Patients in Belgium are legally considered 'minor' when younger than 18 years and 'child' when younger than 15 years.

\section{Variables}

A prospectively designed template was used to register data for all patients: age, gender, country of origin (the country the patient was born in, or lived in before fleeing home for the first time), date of arrival in Belgium, whether and when patients had requested or 
received an appointment at the Belgian Immigration Office or were already officially registered as asylum seeker, location of shelter, all physical and mental symptoms, the 'chief complaint' and all pre-existing comorbidities. ${ }^{20}{ }^{21}$ One primary diagnosis per patient was recorded according to a list of 50 possible diagnoses, adapted from case descriptions in the WHO 'Communicable disease control in emergencies' field manual, the Sphere Project Handbook and a template used in previous humanitarian operations. $^{20} 2223$ Post hoc, trained physicians classified these diagnoses into categories, adapted from International Classification of Diseases Tenth Edition (ICD-10) as described in table 2. ${ }^{24}$ All patients with clinical signs of local or generalised infection were classified as a subgroup of 'infectious diseases'. Finally, referral was recorded.

\section{Data sources}

MdM trained all personnel in collecting data, which were anonymised according to the Helsinki Declaration, and introduced in an Excel database. ${ }^{5} \mathrm{~A}$ data sharing and research collaboration agreement was signed between MdM and the Research Group on Emergency and Disaster Medicine, Vrije Universiteit Brussel, Belgium.

\section{Bias}

Data were recorded by different healthcare providers, and the anonymous records did not allow distinguishing patients possibly inserted twice, potentially introducing a sampling bias. Diagnoses were classified post hoc, possibly introducing a categorisation bias.

\section{Statistical methods}

Patients with missing or unreadable data were excluded. Descriptive statistics for discrete outcome variables were presented as frequencies (n), proportions (\%) and for quantitative variables (age, number of patients) as measures of central tendency and dispersion (median, range, IQR). The analyses were broken down for age categories $(<5,5-14$ and $>15$ years $)$, gender and period (weeks).

Multiple logistic regression analysis was performed to identify factors associated with the asylum seekers' health problems, by using 'infection' as an outcome variable, by using origin (other vs Syria, Iraq, Morocco and Afghanistan), age category (0-15, >15 years), gender, arrival time in Belgium, asylum state and shelter location as predictors. Analyses were carried out by using IBM SPSS V.23.0. All tests were performed using an $\alpha$-level of 0.05 .

\section{RESULTS}

\section{Participants}

MdM examined 4037 patients in total, with a median of 137 per day (range 23-199) as shown in online supplementary figure S1. After exclusion of 130 incomplete forms, 3907 patients were included and analysed.

\section{Descriptive data}

Of all included patients, 3355 (86\%) were male, 510 $(13 \%)$ female and the gender of $42(0.8 \%)$ was unknown. Median age was 28 years (range 0-93; IQR 12). As figure 1 and online supplementary figure $S 2$ illustrate: $78 \%(\mathrm{n}=3049)$ were adult men, 9\% ( $\mathrm{n}=355)$ adult women and over $10 \%(\mathrm{n}=391)$ minors, of whom 303 were children $(8 \%)$, including $149(4 \%)$ aged 5-14 and $153(4 \%)$ aged under five. The age of $86(2 \%)$ adults and children was unknown. The outpatient

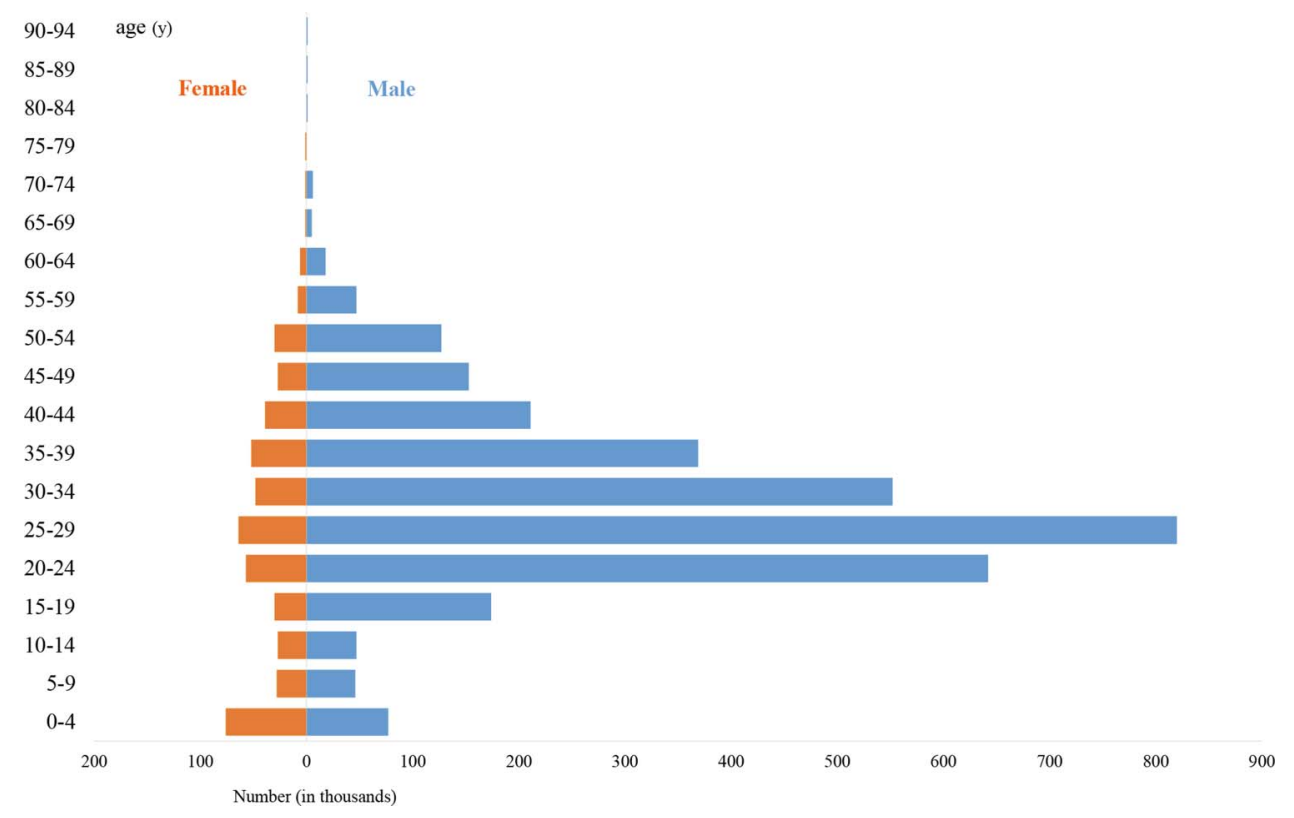

Figure 1 Age distribution of patients by gender. 
assistance teams provided care to 46 patients $(1.18 \%)$ of whom two had to be referred for advanced care.

The region of origin is presented in figure 2. Patients came from 63 different countries (as presented in online supplementary figure S3), but most were from Iraq $(\mathrm{n}=1950 / 3778 ; 52 \%)$, Syria $(\mathrm{n}=737 ; 20 \%)$, Morocco $(\mathrm{n}=365 ; 10 \%)$, Afghanistan $(\mathrm{n}=117 ; 3 \%)$ and Palestine $(\mathrm{n}=96 ; 3 \%)$. Some $1 \%(\mathrm{n}=42)$ were stateless or came from other continents.

The time interval between arrival in Belgium and consultation, the state of asylum procedure and location of shelter are presented in table 1.

\section{Outcome data}

A total of 5768 symptoms (106 different types) were recorded: 2486 patients (64\%) had one single symptom, $1039(27 \%)$ expressed two, $320(8 \%)$ three and $61(2 \%)$ four or more symptoms.

The most common symptoms were: cough $(n=619 /$ $3907 ; 16 \%)$, sore throat $(\mathrm{n}=590 ; 15 \%)$, tooth pain $(\mathrm{n}=406 ; 10 \%)$, rhinorrhoea $(\mathrm{n}=397 ; 10 \%)$, headache $(\mathrm{n}=374 ; 10 \%)$, limb pain $(\mathrm{n}=248 ; 6 \%)$, skin wounds $(\mathrm{n}=236 ; 6 \%)$, influenza-like symptoms $(\mathrm{n}=154 ; 4 \%)$, accidental trauma $(\mathrm{n}=151 ; 4 \%)$, lack of chronic medication $(\mathrm{n}=138 ; 4 \%)$ and abdominal pain $(\mathrm{n}=130 ; 3 \%)$. Some $3 \%$ reported fever $(\mathrm{n}=101), 2 \%$ anxiety $(\mathrm{n}=82)$ and more than $3 \%(n=126)$ re-presented for follow-up.

Categorised according to ICD-10, 56\% of all patients expressed respiratory symptoms $(\mathrm{n}=2198), 12 \%$ had digestive symptoms $(\mathrm{n}=482), 12 \%$ had musculoskeletal symptoms $(n=458), 11 \%$ were injured $(n=429), 11 \%$ had neurological symptoms $(\mathrm{n}=427), 10 \%$ had skin problems $(\mathrm{n}=406)$ and $10 \%$ expressed dental symptoms $(\mathrm{n}=406) .{ }^{24}$ All other categories represented $<5 \%$ of all patients.

More than $7 \%$ of patients reported comorbidities $(n=279)$, most commonly arterial hypertension $(n=103)$

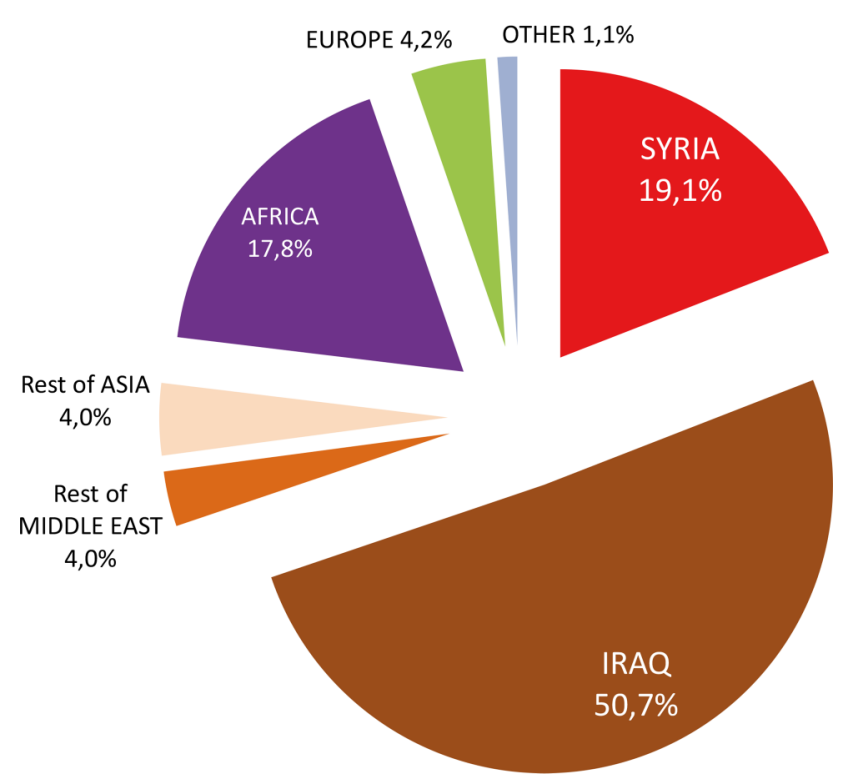

Figure 2 Countries and regions of origin of asylum seekers.

\begin{tabular}{|c|c|c|}
\hline & $\mathbf{n}$ & Per cent \\
\hline \multicolumn{3}{|l|}{ Time interval of arrival in Belgium } \\
\hline $0-7$ days & 2251 & 57.6 \\
\hline $8-31$ days & 629 & 17.7 \\
\hline $32-365$ days & 338 & 8.7 \\
\hline$>365$ days & 240 & 6.1 \\
\hline Unknown & 386 & 9.9 \\
\hline \multicolumn{3}{|l|}{ Asylum procedure } \\
\hline $\begin{array}{l}\text { Appointment at BIO to start } \\
\text { procedure }\end{array}$ & 1292 & 33.1 \\
\hline $\begin{array}{l}\text { No appointment at BIO to start } \\
\text { procedure }\end{array}$ & 1006 & 25.7 \\
\hline $\begin{array}{l}\text { Asylum procedure initiated, waiting } \\
\text { for decision }\end{array}$ & 167 & 4.3 \\
\hline Asylum request denied & 69 & 2.3 \\
\hline Not applicable & 91 & 2.3 \\
\hline Unknown & 1282 & 32.8 \\
\hline \multicolumn{3}{|l|}{ Location of accommodation } \\
\hline Brussels refugee camp (tents) & 2209 & 57.8 \\
\hline Other refugee camps & 495 & 13.0 \\
\hline Governmental asylum seeker centres & 362 & 9.3 \\
\hline Open air & 77 & 2.0 \\
\hline Relatives and friends & 29 & 0.7 \\
\hline Foster family & 17 & 0.4 \\
\hline Other & 51 & 1.3 \\
\hline Unknown & 576 & 14.7 \\
\hline
\end{tabular}

and/or diabetes $(\mathrm{n}=96)$. Patients also reported asthma $(n=19)$, old fractures $(n=15)$, epilepsy $(n=14)$, rheumatism $(n=10)$, recent delivery $(n=7)$, neoplasms $(n=6)$, gastrointestinal $(n=5)$, genitourinary $(n=4)$ or mental disorders $(n=3)$.

Of patients with interrupted maintenance treatment $(\mathrm{n}=138), 72$ had comorbidities: diabetes (24), hypertension (14), asthma (12), epilepsy (8), psychiatric disorders (2) and withdrawal (2). Seven reported lost eyewear, while six infants lacked paediatric formula.

\section{Main results}

As represented in figure 3 and table 2, the most common primary diagnoses consisted of upper respiratory tract infections (31\%), dental caries (8\%), skin infections $(8 \%)$, gastroenteritis $(7 \%)$, skin wounds and burns $(6 \%)$, musculoskeletal disorders $(6 \%)$ and accidental trauma $(6 \%)$. Mental disorders were present in $2 \%$. No patient died, one was resuscitated and $35(1 \%)$ were victims of intentional violence in their country of origin, or during the journey to Brussels. Two women had just delivered, and five parents presented with newborn babies.

Table 2 and figure 4 indicate the distribution of diagnostic categories. The most frequent were respiratory disorders $(35.5 \%)$, far ahead of injury $(11.6 \%)$, dental $(9.5 \%)$, skin $(8.6 \%)$, digestive $(7.8 \%)$ and musculoskeletal diagnoses $(6.1 \%)$. In 19 cases $(0.5 \%)$, there was no 


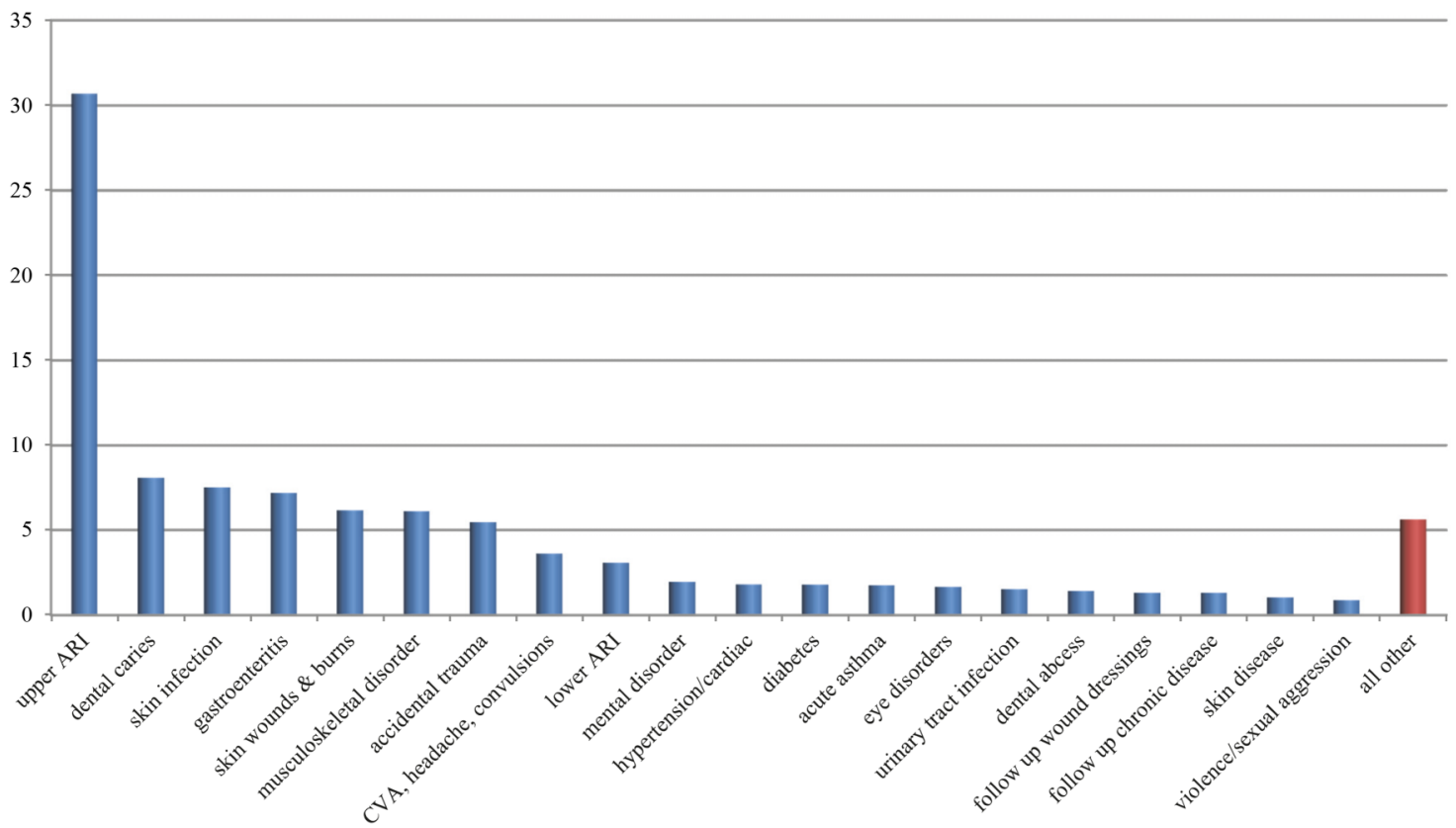

Figure 3 Twenty most common primary diagnoses observed in asylum seekers (\%).

actual medical or mental diagnosis, but the patient requested personal attention or sought assistance for social problems.

Analysis of the distribution of diagnostic categories per week did not reveal any considerable changes over time.

\section{Subgroup analyses}

Features of infection were found in $1900(49 \%)$ patients, with an even higher frequency $(63 \%)$ in children younger than 5 years.

The multiple logistic regression analysis in table 3 shows that asylum seekers from Syria and Iraq, and children have a higher risk for infection. We did not detect any other significant risk factors.

Children aged under 5 years represented $4 \%$ of the population, with equally distributed gender and a median age of two (range $0-5$; IQR 3 ). The majority originated from Middle East countries ( $\mathrm{n}=118 ; 77 \%)$, median time in Belgium was 3 days (range 0-1500; IQR 9 ) and most took shelter in tents $(n=94 ; 61 \%)$. The distribution of diagnostic categories indicates that $50 \%$ had respiratory diseases $(\mathrm{n}=76), 20 \%$ digestive disorders $(\mathrm{n}=30), 14 \%$ skin disorders $(\mathrm{n}=21)$ and $7 \%$ suffered from injuries $(n=10)$. Five $(3 \%)$ were newborns of whom one had to be hospitalised for bronchiolitis with severe dyspnoea.

Patients were asked to re-present for follow-up in 3\% cases $(n=121)$ to the field hospital, and in $4 \% \quad(n=152)$ to ambulant consultations, mainly for arterial tension and blood glucose measurements. Referrals were organised for 412 patients (11\%): 205 to dentists (5\%), 117 (3\%) to emergency departments, 70 to psychotherapists $(2 \%)$ and $20(0.5 \%)$ to mother and newborn care consultations. Children younger than 5 years were referred 27 times (18\% of young children): 15 to ambulant follow-up, 6 to newborn consultations and 2 each to emergency departments, dentists and psychiatrists.

\section{DISCUSSION}

\section{Key results}

Most asylum seekers arriving in Brussels were young men, in contrast to the usual population distribution in internally displaced persons and refugee camps $(50 \%$ children, $30 \%$ women and $20 \%$ men). ${ }^{22}$ The shortest route between Syria and Brussels is $4000 \mathrm{~km}$, unsuited for children, women and older men, who rather remained in refugee camps near their country of origin. $^{11}$ 25-28

Almost half of the asylum seekers, and two-thirds of children younger than 5 years suffered from infections. The multiple logistic regression analysis suggests that asylum seekers from Syria and Iraq, and children have a higher risk of infection. Also, the Immigration Office registration delay postponed entitlement to shelter, food and (medical) assistance, and the encampment in austere conditions possibly contributed to the large proportion of infections. 121429

The overwhelming presence of (mostly upper) acute respiratory infections (ARI) is consistent with existing reports as visualised in table $4 .{ }^{8} 111516202530$ A possible explanation is that most people from the Middle East and Africa arrived in autumn, in a cold and rainy environment, and were confronted with the typical respiratory viruses of Western Europe they were never exposed to before. ${ }^{14}{ }^{29}$ Owing to huddling in refugee camps, and many patients coughing, these viruses spread rapidly. ${ }^{14}$ 
Table 2 Diagnostic categories, primary diagnoses and case descriptions

\begin{tabular}{|c|c|c|c|c|c|c|}
\hline Category & $\mathbf{n}$ & Per cent & Primary diagnosis & $\mathbf{n}$ & Per cent & Case descriptions \\
\hline No diagnosis & 19 & 0.5 & No medical diagnosis & 19 & 0.5 & Social problem, attention seeker \\
\hline \multirow[t]{3}{*}{ Respiratory } & 1388 & 35.5 & Upper respiratory tract infection & 1199 & 30.7 & Ear, nose, throat, sinus, larynx infections, influenza (upper ARI) \\
\hline & & & Lower respiratory tract infection & 120 & 3.1 & Dyspnoea, and raised respiratory rate, signs of lower ARI \\
\hline & & & Asthma exacerbation & 69 & 1.8 & Wheezing and/or respiratory oppression \\
\hline \multirow[t]{2}{*}{ Eye and Adnexa } & 67 & 1.7 & Eye disorder & 65 & 1.7 & Eye infection and irritation \\
\hline & & & Vision problem & 2 & 0.1 & Diminished or troubled vision, blindness \\
\hline \multirow[t]{2}{*}{ Dental } & 372 & 9.5 & Dental abscess & 56 & 1.4 & Clinical suspicion of dental abscess \\
\hline & & & Dental caries & 316 & 8.1 & Caries with or without pain \\
\hline \multirow[t]{5}{*}{ Digestive } & 303 & 7.8 & Watery diarrhoea/abdominal & 281 & 7.2 & Loose stools, vomiting, abdominal pain, intestinal parasitosis \\
\hline & & & Bloody diarrhoea & 5 & 0.1 & Loose stools with visible blood (suspicion of dysentery) \\
\hline & & & Malnutrition & 15 & 0.4 & Clinical, weight/height $>70 \%$ or MUAC $<110 / 160$ (child/adult) \\
\hline & & & Cholera & 0 & 0.0 & Severe dehydrating diarrhoea/confirmed case in a non-endemic area \\
\hline & & & Jaundice & 2 & 0.1 & Acute onset of icterus (skin, conjunctivae, urine) \\
\hline \multirow[t]{3}{*}{ Neurological } & 142 & 3.6 & Suspected meningitis & 1 & 0.0 & Fever and clinical signs of meningeal irritation \\
\hline & & & Flaccid paralysis & 0 & 0.0 & Paralysis in children of $\geq 1 \mathrm{limb}$, incl. Guillain-Barré or any polio suspicion \\
\hline & & & CVA, headache, convulsions & 141 & 3.6 & Headache, convulsions, stroke, coma \\
\hline \multirow[t]{3}{*}{ Genitourinary } & 97 & 2.5 & Sexual transmittable disease & 19 & 0.5 & Suspected STD, vaginal infections with fluor, genital infection \\
\hline & & & Urinary tract infection & 59 & 1.5 & Dysuria, alguria, pollakisuria, with/without fever, flank pain, or + dipstick \\
\hline & & & Gynaecological disorder & 19 & 0.5 & Irregular menses, breast problems, vaginal bleeding, abortion \\
\hline \multirow[t]{5}{*}{ Peripartum } & 28 & 0.7 & Neonatal illness & 1 & 0.0 & Newborns with problems \\
\hline & & & Neonatal tetanus & 0 & 0.0 & Neonate not sucking/crying normally, rigidity, convulsions \\
\hline & & & Healthy newborn baby & 4 & 0.1 & Healthy baby $<3$ weeks old \\
\hline & & & Delivery & 2 & 0.1 & Mother: imminent delivery or postpartum (<3 weeks) \\
\hline & & & (presumed) pregnant & 21 & 0.5 & Suspected or confirmed pregnancy \\
\hline \multirow[t]{2}{*}{ Skin } & 335 & 8.6 & Skin infection & 294 & 7.5 & Redness, pain, abcedation with signs of local infection \\
\hline & & & Skin affection & 41 & 1.0 & Redness, xerosis, urticaria, psoriasis without infection \\
\hline \multirow[t]{9}{*}{ General } & 154 & 3.9 & Surgical cases other than trauma & 24 & 0.6 & Herniations, swollen testicles, cysts, haemorrhoids, ... \\
\hline & & & Fever of unknown origin & 9 & 0.2 & $>37 ., 5^{\circ} \mathrm{C}$ axillary or $>38.0^{\circ} \mathrm{C}$ rectal, without specific diagnosis \\
\hline & & & Malaria & 0 & 0.0 & Confirmed or suspected malaria, simple or serious \\
\hline & & & Measles & 0 & 0.0 & Fever and clinical suspicion of measles (vaccinated or not) \\
\hline & & & Clinical anaemia & 3 & 0.1 & History, pallor, weakness \\
\hline & & & Diabetes & 70 & 1.8 & Diabetes as main problem, or crisis/ketoacidosis \\
\hline & & & Other & 35 & 0.9 & All that is not classified elsewhere \\
\hline & & & Intoxication & 8 & 0.2 & Suspected or confirmed substance abusus \\
\hline & & & Neoplasm & 5 & 0.1 & Suspected or confirmed oncological disease \\
\hline Mental & 76 & 1.9 & Mental disorder & 76 & 1.9 & PTSD, insomnia, stress, suspicious aspecific symptoms \\
\hline \multirow[t]{2}{*}{ Violence } & 35 & 0.9 & Trauma from aggression & 34 & 0.9 & Trauma due to intentional individual injury including rape \\
\hline & & & CBRN & 1 & 0.0 & Injury from chemical/biological/radiological/nuclear assaults \\
\hline \multirow[t]{2}{*}{ Injury } & 454 & 11.6 & Accidental trauma & 213 & 5.5 & Accidental trauma from incident, accident (non-violent trauma) \\
\hline & & & Acute wounds & 241 & 6.2 & Non-intentional acute skin wounds, burns \\
\hline Musculoskeletal & 239 & 6.1 & Musculoskeletal disorder & 239 & 6.1 & Non-traumatic pain (muscles, back, pelvic belt, joints), rheumatic \\
\hline Circulatory & 71 & 1.8 & Hypertension/cardiac disorder & 71 & 1.8 & Symptomatic hypertension, palpitations, angina pectoris \\
\hline
\end{tabular}




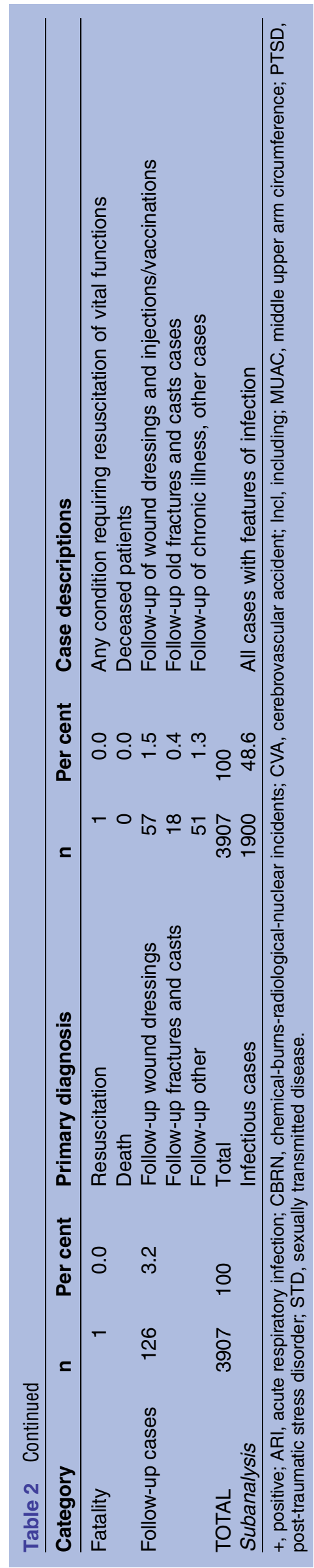

This carries a possible burden, as ARIs are a major cause of morbidity and mortality among displaced people. ${ }^{30}$

Contrarily, the same conditions did not result in a similar spread of intestinal, genitourinary or eye infections, as is usually seen in internally displaced persons or refugee camps. ${ }^{15} 202829$ This was possibly owing to appropriate management of sanitary facilities by MdM.

The important share of dental problems is unusually high for any refugee camp, but consistent with other reports on Syrian refugees. ${ }^{11} 1631$ It must be considered that most patients were Iraqi who already fled their country after the 2002 invasion to become refugees in Syria, where access to dental or any healthcare was limited. ${ }^{11} 32$ Their long, exhausting travel with limited healthcare facilities might have contributed to transform caries into dental abscesses.

While undertaking their journey, many of the asylum seekers halted in several different camps along the way, sleeping in any fleabag they could find, possibly resulting in the many scabies infections observed. ${ }^{8} 141528$ The proportion of skin infections is consistent with available European reports, but higher than seen in other internally displaced persons and refugee populations analysed the same way. 81520

Violent trauma, injuries and musculoskeletal problems were present in almost $20 \%$ of the asylum seekers, with a wide variety of causes: accidental trauma was usually from falls, not always related to the journey; acute wounds were either blisters on feet from walking long distances, or infected wounds caused by barbed wire. ${ }^{33}$ The musculoskeletal issues-back and limb pain in young men-were often related to the journey as well. $^{8} 12 \quad 15 \quad 25$ The number of war-related injuries was limited; most had been treated long before arrival in Brussels. ${ }^{25}$

The proportion of mental disorders was rather low $(2 \%)$, in contrast to other studies reporting incidences of up to one-third. ${ }^{8} 12273435$ Even though MdM provided a separate tent (with sufficient privacy and constant availability of interpreters), it is still possible that language barriers, limited time per consultation and the fact that most patients were young men from Middle East countries-not easily expressing emotions to strangers in tents-might have contributed to this low proportion. We do suspect under-reporting of mental problems, as MdM recorded more use of secondary psychological consultations in the field hospital than was registered in this study.

We did not detect a changing pattern of diagnostic categories over time, possibly because the population of the camp was replaced regularly with new arrivals.

Referral to EDs was needed in $3 \%$ of the consultations, for varying reasons: suspected fractures, stitches (as stitching in field hospitals encompasses risks of wound infection), pneumonia, confusion and convulsions or syncope, oncological patients who ran out of maintenance treatment. Many referrals were made to dentists' offices, as well as to psychiatrists-psychologist 


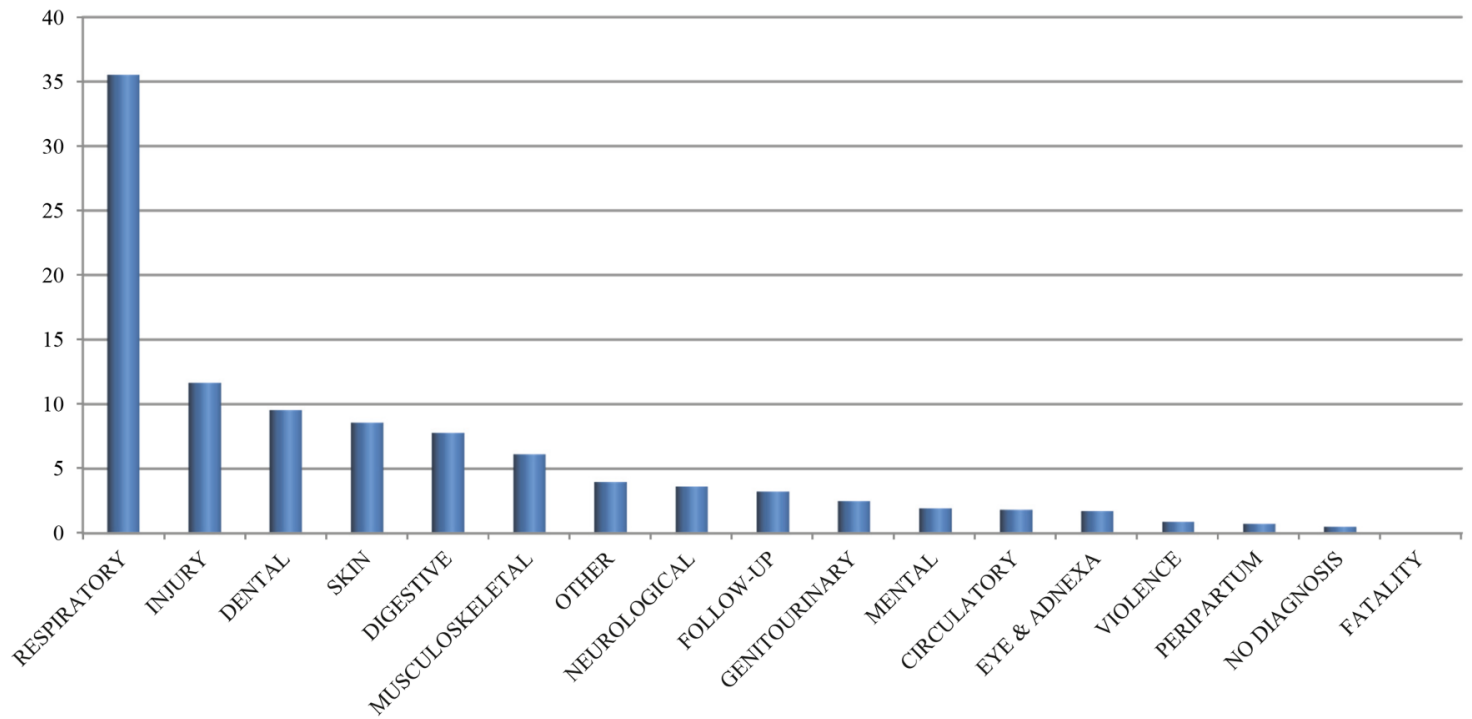

Figure 4 Proportion of diagnostic categories observed in asylum seekers (\%).

\begin{tabular}{|c|c|c|c|c|}
\hline & \multirow[b]{2}{*}{ OR } & \multicolumn{2}{|c|}{$95 \% \mathrm{Cl}$ of $\mathrm{OR}$} & \multirow[b]{2}{*}{ p Value } \\
\hline & & Lower & Upper & \\
\hline \multicolumn{5}{|c|}{ Origin (reference: other countries) } \\
\hline Syria & 1.91 & 1.54 & 2.38 & $<0.0001$ \\
\hline Iraq & 1.85 & 1.54 & 2.21 & $<0.0001$ \\
\hline Morocco & 0.99 & 0.76 & 1.29 & 0.95 \\
\hline Afghanistan & 1.42 & 0.95 & 2.12 & 0.09 \\
\hline \multicolumn{5}{|c|}{ Gender (reference: male) } \\
\hline Female & 0.77 & 0.63 & 0.95 & 0.01 \\
\hline \multicolumn{5}{|c|}{ Age (reference $\geq 15$ years) } \\
\hline$<15$ years & 1.64 & 1.28 & 2.10 & $<0.0001$ \\
\hline
\end{tabular}

when signs of post-traumatic stress disorder were present. Referrals to ambulant consultations were ordinarily for deregulated diabetes and arterial hypertension.

The prevalence of $7 \%$ of non-communicable chronic diseases (mainly diabetes, hypertension and asthma) found in this study population was lower than the range in earlier reports, possibly due to the limited number of aged asylum seekers. ${ }^{26}$ Some 138 patients $(4 \%)$ lacked maintenance treatment medication, of whom 72 had chronic comorbidities like diabetes and hypertension, and were therefore at risk for deregulation of their clinical condition. For these patients, MdM provided all necessary medication and materials (like insulin, $\beta$ blockers, puffs, blood glucose meters, urine ketone strips) and provided follow-up or referral.

Nineteen patients $(0.5 \%)$ did not get a specific medical diagnosis, but were categorised as seeking attention for their distressing situation or looking for non-medical support.

Long-term conditions (including vector-borne and blood borne infections such as leishmaniasis, malaria, hepatitis B and Helicobacter pylori) may have been underpresented or under-diagnosed, as healthcare providers focused more on identifying acute conditions.

It is difficult to draw conclusions from this study about the importation of communicable diseases, one of the mythical concerns raised about immigrants. ${ }^{8} \quad 12 \quad 14$ Belgium screens asylum seekers for tuberculosis, but not for HIV, measles, polio or pertussis, diseases usually quoted in the context of refugees. ${ }^{81529} 32{ }^{36}$ Whenever suspicion was raised, patients were transferred to hospitals for investigation. None of these tests yielded positive results in September 2015.

\section{Limitations and strengths}

This study has several limitations. The study included only patients self-presenting or referred by outpatient assistance teams to the field hospital in the autumn of 2015, preventing extrapolation to all asylum seekers, and other seasons. A number of diagnoses remained tentative, since laboratory and imaging tests were unavailable. Patient anonymity prevented longitudinal follow-up. The lack of uniform standards to collect symptoms and diagnoses makes comparison with other data sets challenging. ${ }^{6} 7$

The strength of this study is the considerable number of well-documented symptoms and physician diagnoses in asylum seekers arriving in Western Europe. To the best of our knowledge, this has not been reported in such detail before. Since Belgium registered 5512 asylum seekers in September 2015, this study sample is of considerable proportion. ${ }^{2}$

\section{Interpretation}

Asylum seekers arriving in a refugee camp in Brussels after a long and hazardous journey suffer mostly from respiratory, dental, skin and digestive diseases, and one of seven is injured. Half of this population shows 


\begin{tabular}{|c|c|c|c|c|c|c|c|c|c|c|c|c|c|c|c|}
\hline This study & $\mathrm{RC}$ in Brussels & 35.5 & 1.7 & 9.5 & 7.8 & 2.5 & 8.6 & 1.9 & 0.9 & 12.5 & 6.1 & 1.8 & 48.6 & 7.0 & 3907 \\
\hline Alberer et al ${ }^{15}$ & $\mathrm{RC}$ in Germany & 23.0 & 3.6 & 3.5 & 9.7 & 5.3 & 7.7 & 1.1 & & & 7.7 & 2.2 & 39.9 & 2.6 & 548 \\
\hline Marquard et $a 1^{16}$ & $\begin{array}{l}\text { Refugee minors in } \\
\text { Germany }\end{array}$ & & & 20.6 & & & & 13.7 & & & & & 58.8 & $<2.0$ & 102 \\
\hline Bischoff et $a^{\beta}$ & $\begin{array}{l}\text { Refugees in } \\
\text { Switzerland }\end{array}$ & 14.1 & & & & & 8.8 & 13.7 & & 8.6 & 14.5 & 4.4 & 6.3 & & 979 \\
\hline McKenzie at a $\left.\right|^{34}$ & Refugees in Jordan & & & & & & & 1.8 & & & & & & & 2526 \\
\hline Doocy et a $\mathrm{P}^{6}$ & Refugees in Jordan & & & & & & & & & & & & & 50.3 & 1550 \\
\hline Gammouh et a $P^{7}$ & Jordan RC & & & & & & & 29.5 & & & & & & 30.3 & 765 \\
\hline $\mathrm{UNHCR}^{28}$ & $\mathrm{RC}$ in Jordan & 29.7 & 2.2 & 2.7 & 5.6 & & 3.5 & 1.3 & 0.5 & 4.3 & & 5.3 & 72.1 & 21.8 & 694280 \\
\hline $\mathrm{UNHCR}^{28}$ & $\mathrm{RC}$ in Iraq & 56.4 & 3.3 & & 11.7 & 4.7 & 4.8 & 0.5 & 0.2 & 2.2 & 0.1 & 3.2 & 89.6 & 7.4 & 127401 \\
\hline $\mathrm{UNHCR}^{28}$ & RC in Lebanon & 27.1 & & & 4.5 & 3.0 & 4.6 & 1.4 & 0.1 & 0.9 & & 2.0 & 89.3 & 8.3 & 52060 \\
\hline $\begin{array}{l}\text { North and } \\
\text { Pfefferbaum }\end{array}$ & $\begin{array}{l}\text { Review mental } \\
\text { health }\end{array}$ & & & & & & & $11-38$ & & & & & & & $\begin{array}{l}222 \\
\text { studies }\end{array}$ \\
\hline
\end{tabular}

*Studies on IDP and refugees not from the Syrian crisis.

ARI, acute respiratory infections; FH, field hospital; IDP, internally displaced persons; MSF, Médecins Sans Frontières; NCD, non-communicable diseases; RC, refugee camp. 
features of infection, with asylum seekers from Syria and Iraq, and children being most vulnerable.

The high proportion of respiratory diseases, as in any internally displaced persons or refugee camp worldwide, urges to take ARI preventive measures: adequate shelter, overcrowding reduction, malnutrition prevention and treatment, and scaling up vaccination coverage, in order to meet the Health 2020 policy framework goals. ${ }^{29} 30$ Adequate sanitary facilities are imperative to prevent the spread of infections. Early and resolute healthcare may avoid short-term and long-term complications of infectious, dental, mental and mother and child problems, which otherwise could lead to higher healthcare expenditure for the hosting population. ${ }^{12} 25$

In emergency medical teams treating asylum seekers, there is an early role for general and emergency physicians, paediatricians, gynaecologists, midwives, dentists and interpreters. ${ }^{11} 16{ }^{30-32}$ Scaling up with diabetes and hypertension specialists and psychologists is recommended. ${ }^{6} 81226273435$ In our experience, it is much easier to recruit volunteers for the initial emergency part.

\section{Generalisability}

The results of this study can help to better organise healthcare for asylum seekers residing in camps, particularly with respect to the composition of the medical assistance teams and the medical resources. ${ }^{6}{ }^{7}$ However, in order to meet the specific and changing needs of asylum seekers arriving in Europe, more research is needed to compare and confirm our findings.

The development of a standardised template to prospectively collect and subsequently analyse and report health might make a substantial contribution to provide the evidence base for the effectiveness and efficiency of the preparation, management and mitigation of humanitarian emergencies. ${ }^{46721}$

\section{Author affiliations}

${ }^{1}$ Department of Emergency Medicine, Universitair Ziekenhuis Brussel, Brussels, Belgium

${ }^{2}$ Research Group on Emergency and Disaster Medicine, Vrije Universiteit Brussel, Brussels, Belgium

${ }^{3}$ Medical Department, Operations Department, Médecins du Monde/Doctors of the World Belgium, Brussels, Belgium

${ }^{4}$ Department of Public Health, Biostatistics and Medical Informatics Research Group, Vrije Universiteit Brussel, Brussels, Belgium

Contributors GvB, FBC, SM and RB conceived and designed the study. GvB, $\mathrm{FBC}, \mathrm{SM}, \mathrm{XdB}$ acquired the data. $\mathrm{RB}, \mathrm{GvB}, \mathrm{XdB}$ and $\mathrm{SM}$ analysed and interpreted the data. GvB, FBC, $S M, X d B$ and RB drafted the article. GvB, FBC $\mathrm{SM}, \mathrm{XdB}, \mathrm{RB}, \mathrm{MD}$ and IH revised the article. GvB, FBC, SM, XdB, RB, MD and $\mathrm{IH}$ approved the final version of the article to be published.

Funding Fees for open access publication will be paid by the Research Group on Emergency and Disaster Medicine, Vrije Universiteit Brussel, Brussels, Belgium.

\section{Competing interests None declared.}

Ethics approval Approval of the Commission of Medical Ethics (0.G. 016) of the Universitair Ziekenhuis Brussel, Brussels, Belgium was obtained (B.U.N. 143201526433)
Provenance and peer review Not commissioned; externally peer reviewed.

Data sharing statement Extra data can be accessed via the Dryad data repository at http://datadryad.org/ with the doi:10.5061/dryad.p9b21. A data sharing and research collaboration agreement was signed between Médecins du Monde and the Research Group on Emergency and Disaster Medicine, Vrije Universiteit Brussel, Belgium.

Open Access This is an Open Access article distributed in accordance with the Creative Commons Attribution Non Commercial (CC BY-NC 4.0) license, which permits others to distribute, remix, adapt, build upon this work noncommercially, and license their derivative works on different terms, provided the original work is properly cited and the use is non-commercial. See: http:// creativecommons.org/licenses/by-nc/4.0/

\section{REFERENCES}

1. United Nations High Commissioner for Refugees (UNHCR). The 1951 Convention Relating to the Status of Refugees and its 1967 Protocol. Geneva, Switzerland: Office of the UNHCR, Communications and Public Information Service, 1951 and 1967. http://www.unhcr.org/4ec262df9.html (accessed 29 Jun 2016).

2. Office of the Commissioner General for Refugees and Stateless Persons. Asylum statistics September 2015. http://www.cgra.be/sites/ default/files/asylumstat_september_2015.pdf (accessed 29 Jun 2016).

3. European Commission, Eurostat. Record number of over 1.2 million first time asylum seekers registered in 2015. http://ec.europa.eu/ eurostat/web/products-press-releases/-/3-04032016-AP (accessed 29 Jun 2016).

4. Debacker M, Hubloue I, Dhondt E, et al. Utstein-style template for uniform data reporting of acute medical response in disasters. PLoS Curr 2012;4:e4f6cf3e8df15a.

5. World Medical Association. WMA declaration of Helsinki-ethical principles for medical research involving human subjects. Bull World Health Organ 2001;79:373-4.

6. Gerdin M, Clarke M, Allen C, et al. Optimal evidence in difficult settings: improving health interventions and decision making in disasters. PLoS Med 2014;11:e1001632.

7. Evidence Aid Priority Setting Group EAPSG. Prioritization of Themes and Research Questions for Health Outcomes in Natura Disasters, Humanitarian Crises or Other Major Healthcare Emergencies. PLoS Curr 2013;5:ecurrents.dis. c9c4f4db9887633409182d2864b20c31. doi:10.1371/currents.dis. c9c4f4db9887633409182d2864b20c31.

8. Bischoff $A$, Schneider M, Denhaerynck K, et al. Health and ill health of asylum seekers in Switzerland: an epidemiological study. Eur $J$ Public Health 2009;19:59-64.

9. Dick B. Diseases of refugees-causes, effects and control. Trans $R$ Soc Trop Med Hyg 1984;78:734-41.

10. Clinton-Davis L, Fassil Y. Health and social problems of refugees. Soc Sci Med 1992;35:507-13.

11. Mateen F, Carone M, Al-Saedy $\mathrm{H}$, et al. Medical conditions among Iraqi refugees in Jordan: data from the United Nations Refugee Assistance Information System. Bull World Health Organ 2012;90:444-51.

12. Langlois E, Haines A, Tomson G, et al. Refugees: towards better access to health-care services. Lancet 2016;387:319-21.

13. WHO Regional Office for Europe. Migration and health: key issues. http://www.euro.who.int/en/health-topics/health-determinants/ migration-and-health/migrant-health-in-the-european-region/ migration-and-health-key-issues (accessed 29 Sep 2016).

14. Stich A. Coming in to the cold-access to health care is urgently needed for Syrian refugees. Travel Med Infect Dis 2015;13:445-6.

15. Alberer M, Wendeborn M, Löscher T, et al. Erkrankungen bei Flüchtlingen und Asylbewerbern. Dtsch Med Wochenschr 2016;141: e8-15.

16. Marquardt L, Krämer A, Fischer F, et al. Health status and disease burden of unaccompanied asylum-seeking adolescents in Bielefeld, Germany: cross-sectional pilot study. Trop Med Int Health 2016;21:210-18.

17. Pfortmueller C, Schwetlick M, Mueller T, et al. Adult asylum seekers from the Middle East including Syria in central Europe: what are their health care problems? PLOS ONE 2016;11:e0148196.

18. Burnett $A$, Peel $M$. Health needs of asylum seekers and refugees. BMJ 2001;322:544-7.

19. Norton I, von Schreeb J, Aitken $\mathrm{P}$, et al. Classification and minimum standards for foreign medical teams in sudden onset disasters. Geneva: World Health Organisation, 2013. 
20. van Berlaer G, Staes T, Danschutter D, et al. Disaster preparedness and response improvement: comparison of the 2010 Haiti earthquake-related diagnoses with baseline medical data. Eur J Emerg Med Published Online First: 22 Mar 2016. doi:10.1097/ MEJ.0000000000000387

21. Mowafi $\mathrm{H}$, Dworkis D, Bisanzo M, et al. Making recording and analysis of chief complaint a priority for global emergency care research in low-income countries. Acad Emerg Med 2013;20:1241-5.

22. Connolly MA, ed. World Health Organisation (WHO/CDS). Communicable disease control in emergencies: a field manual. Geneva: World Health Organisation, 2005:204-31.

23. The Sphere Project. Sphere Handbook 2011 (English). http://www. sphereproject.org/handbook/ (accessed 29 Jun 2016).

24. WHO. International statistical classification of diseases and health related problems: 10th revision. Geneva: WHO, 2010

25. Escobio F, Echevarria J, Rubaki S, et al. Health assistance of displaced people along the Balkan route. Lancet 2015;386:2475.

26. Doocy S, Lyles E, Roberton T, et al. Prevalence and care-seeking for chronic diseases among Syrian refugees in Jordan. BMC Public Health 2015;15:1097.

27. Gammouh O, Al-Smadi A, Tawalbeh L, et al. Chronic diseases, lack of medications, and depression among Syrian refugees in Jordan, 2013-2014. Prev Chronic Dis 2015;12:E10.
28. UNHCR. At a glance: health data for Syrian refugees (Iraq, Jordan and Lebanon). UNHCR, 2014. https://data.unhcr.org/syrianrefugees/ download.php?id=5635 (accessed 29 Jun 2016).

29. Connolly M, Gayer M, Ryan M, et al. Communicable diseases in complex emergencies: impact and challenges. Lancet 2004;364:1974-83.

30. Bellos A, Mulholland K, O'Brien K, et al. The burden of acute respiratory infections in crisis-affected populations: a systematic review. Confl Health 2010;4:3.

31. Calvasina P, Muntaner C, Quiñonez C. The deterioration of Canadian immigrants' oral health: analysis of the Longitudinal Survey of Immigrants to Canada. Community Dent Oral Epidemiol 2015;43:424-32.

32. Ben Taleb Z, Bahelah R, Fouad FM, et al. Syria: health in a country undergoing tragic transition. Int J Public Health 2015;60:S63-72.

33. Smith J, Daynes L. Borders and migration: an issue of global health importance. Lancet Glob Health 2016;4:e85-6.

34. McKenzie E, Spiegel P, Khalifa A, et al. Neuropsychiatric disorders among Syrian and Iraqi refugees in Jordan: a retrospective cohort study 2012-2013. Confl Health 2015;9:10.

35. North CS, Pfefferbaum B. Mental health response to community disasters: a systematic review. JAMA 2013;310:507-18.

36. Van den Brande $\mathrm{P}$, Uydebrouck $\mathrm{M}$, Vermeire $\mathrm{P}$, et al. Tuberculosis in asylum seekers in Belgium. VRGT (Flemish Lung and Tuberculosis Association). Eur Respir J 1997;10:610-14. 